\title{
THE INFLUENCE OF MICROSTRUCTURE OF ARC SPRAYED COATINGS ON WEAR RESISTANCE
}

\author{
Daniel Majewski ${ }^{1}$, Tadeusz Hejwowski', Daniel Łukasik $^{1}$ \\ 1 Lublin University of Technology, Faculty of Mechanical Engineering, Department of Materials Engineering, \\ 36 Nadbystrzycka St., 20-618 Lublin, Poland, e-mail: daniel.majewski@pollub.edu.pl, t.hejwowski@pollub.pl, \\ d.lukasik@pollub.pl
}

Received: 2017.12.12

Accepted: 2018.02.01

Published: 2018.03.01

\begin{abstract}
The paper presents the test results of microstructure and resistance to abrasion and erosive wear of single and double-layer coatings with arc-coated powder wires on the iron matrix. It was shown that adhesion of coatings is in the range of $14.39-24.72$ $\mathrm{MPa}$. The closed porosity of the coatings determined from SEM images is in the range of $0.69-2.45 \%$ and was significantly lower than the porosity determined from the images obtained from the optical microscope, which was $5.49-8.11 \%$. The $95 \mathrm{MXC}$ coating's hardness of the matrix was about $100 \mathrm{HV}_{0.05}$ higher compared to the AMI 100 coating matrix. The intensity of the erosion of AMI 100 coatings was lower than the intensity of the erosion of $95 \mathrm{MXC}$ coatings.
\end{abstract}

Keywords: microstructure, microhardness, wear resistance, sprayed coatings, quantitative metallography.

\section{INTRODUCTION}

Rapidly growing industry has a high demand for new solutions regarding the quality of coatings obtained by using existing and new thermal spraying technologies. One of the major areas of coatings application are devices subjected to abrasive and erosive wear. According to Eyre, the scale of the phenomenon in the industry is around 58\% (abrasive wear is about $50 \%$ and erosion wear is about $8 \%$ ). Other mechanisms of wear are: adhesion $-15 \%$, fretting $-8 \%$, chemical wear $-5 \%$, other $-14 \%$. The type of impact of the abrasive grains on the individual material depends on the parameters of the loads carried by the abrasive grains and the nature of movement in relation to the surface of the material [1].

There is no universally accepted classification of abrasive wear in technical literature. P. Solski, having regard to the different degrees of grain freedom, has divided abrasion into: abrasion by fixed grains (grinding), abrasion by abrasive layer (occurs in the presence of particles in the form of impurities between co-operating machine components), abrasion in abrasive mass (the wearing process of agricultural machinery), abrasive flux (erosion - occurs when the impact process of abrasive grains on the material is dynamic) [2].

Some micro-mechanisms occurring in abrasive wear processes are similar to erosive wear processes. These mechanisms have been described by Winter and Hutchings using the singular sharp-edged particles for research. Microcutting and micro-grooving were observed, as well as the presence of adiabatic shear bands. In the study of micro-mechanisms of abrasive wear, the influence of adhesion forces between the incidence particle and the material on the formation of wear products has been determined as significantly affecting [3]. The erosion wear of ductile materials depends on certain factors, including: incidence angle and particle velocity; shape, size and mechanical properties of the particle; temperature, size and shape of the eroded surface; the 
type of carrier gas or environment, and the presence of admixtures in the abrasive [4].

One of the most important properties of the coatings is their porosity. For cermet coatings, achieving a porosity of less than $5 \%$ is beneficial for improving erosion resistance [5]. In erosion tests of cermet coatings for the $90^{\circ}$ incidence angle, cracking and spattering of large grains were observed in the coating. For a $30^{\circ}$ incidence angle, a significant reduction in roughness was observed due to the presence of micro-cutting processes [6]. Arc-sprayed coatings are used in the case of erosion - corrosion in the fluidised bed boiler. They are obtained from materials such as Ducor (WC - 26\%, Cr - 14\%, B - 1.87\%, Si $1.25 \%, \mathrm{Mn}-0.55 \%)$, Armacor M (B - 3.75\%, Cr $-2.9 \%, \mathrm{Mn}-1.65 \%, \mathrm{Si}-1.6 \%, \mathrm{Fe}-$ other $)$, as well as Alpha $1800(\mathrm{~B}-6.1 \div 9.5 \%, \mathrm{Si}-0.02 \div$ $1 \%, \mathrm{Al}-0.02 \div 1 \%, \mathrm{C}-0.06 \div 0.6 \%$, Fe - other). For the last of the given materials the coating thicknesses losses were 3 to 7 times lower than non-alloy steel at temperatures up to $600{ }^{\circ} \mathrm{C}$ [7].

The micro-structure of arc-coated coatings has been the subject of a few and fragmented publications. The aim of this study was to present the results of the research (porosity, micro-hardness, microstructure, abrasion and erosion wear resistance, adhesion and EDS) on metallic arc-sprayed coatings and micro-structure influence on abrasion and erosion.

\section{METHODOLOGY OF RESEARCH}

The subjects were arc-sprayed coatings on five test panels using the TAFA 8835 arc spraying system (arc current $-250 \mathrm{~A}$, voltage $-32 \mathrm{~V}$, operating pressure $-0.5 \mathrm{MPa})$. For microscopic studies 13CrMo4-5 steel washers were made. Prior to the spraying process, the base materials were sandblasted with loose abrasive. The primer layers were sprayed with $75 \mathrm{~B}$ chemical powder $\mathrm{Al}-4.5 \%$; $\mathrm{Ni}-93.95 \%$ (layer thickness $-0.2 \mathrm{~mm}$ ). The wear resistant layers (layer thickness $-0.3 \mathrm{~mm}$ ) were made of powdered wires -95 MXC with chemical composition $\mathrm{C}-0.15 \%$; Si $1.2-2 \% ; \mathrm{Cr}-26 \div 29 \% ; \mathrm{Mn}-1.1 \div 2 \%$; B -3.3 $\div 4 \%$; Fe - other, and AMI SPRAY ARC 100 with chemical composition $\mathrm{C}-2.8 \%$; $\mathrm{Cr}-19 \%$; Fe - other. Surface roughness studies have shown that $\mathrm{Ra}$ is greater than $40 \mu \mathrm{m}$. Chemical composition of $13 \mathrm{CrMo} 4-5$ steel: C $0.11-0.18 \%$; Mn 0.4 - 0.7\%, Si 0.15 - 0.35\%; Cr $0.7-1 \%$;
Mo $0.4-0.55 \%, \mathrm{Cu}<0.25 \%$; $\mathrm{Ni}<0.35 \%$ and the chemical composition of 10CrMo9-10 steel is C $0.08-0.15 \%$; Mn $0.4-0.6 \%$, Si $0.15-0.50 \%$; Cr $2-2.5 \%$; Mo $0.9-1.1 \%, \mathrm{Cu}<0.25 \%$; Ni $<0.3 \%$.

The materials for the microscopic examination were cut on a Struers Secotom - 10 metallographic cutter with coolant. The selected feed rate for the cut material was $0.1 \mathrm{~mm} / \mathrm{min}$. The cut specimens were housed in a chemo-hardened epoxy resin. The samples were ground and polished on a Mintech Z63 grinding machine. The final polishing step was performed on a $3 \mu \mathrm{m}$ diamond suspension liquid. Microstructure photos were taken on the Nikon Eclipse MA100 microscope equipped with a digital camera. Based on images from microscope, closed porosity analysis was performed. Porosity was measured based on 60 images for each material. The SEM analysis was performed on the PHENOM Pro X scanning microscope to analyse the surface and cross-section of the coatings. Analyses of the porosity of microstructures and images from scanning electron microscope and optical microscope were performed in Image Pro Plus. Open porosity was tested on the basis of the results of 6 SEM images for each sample. Closed porosity was investigated using 15 SEM images for each sample. Micro-hardness was tested by the FM-800 testing machine. Measurements were conducted using the Vickers method (fifteen measurements for each of the six samples of the material). The load was $0,49 \mathrm{~N}$, duration $10 \mathrm{~s}$.

Adhesion tests were performed according to DIN EN 582. The coatings were sprayed on flat surfaces of $\varnothing 40 \times 7.5 \mathrm{~mm}$. The coated surfaces were ground on a magnetic grinder to obtain a uniform geometry of the test surface. The adhesion tests were performed on a Cometech QC-503 B1 $(\mathrm{F} \leq 100 \mathrm{kN})$ testing machine. The durable connection between the spindle and the coating surface was obtained with thermosetting epoxy glue 3M Scotch Weld Epoxy Adhesive 2214.

Erosion tests were carried out using selfconstructed test equipment. The abrasive was fed from the feeder to the nozzle and accelerated in a compressed air stream. $\mathrm{Al}_{2} \mathrm{O}_{3}$ abrasive, with grain size $<0.1 \mathrm{~mm}$ was used. The measured speed of the abrasive using two discs method was $61 \mathrm{~m} / \mathrm{s}$. Measurements were performed three times for each sample. The erosion intensity is calculated as the ratio of the weight loss of the test material to the mass used in the abrasive measurement. The abrasive and test materials were weighed on a RADWAG WAS 220/X. 
Abrasion tests were performed on the T-07 laboratory tester. The pressure of the rubber roller was $22 \mathrm{~N}$. The test time was $300 \mathrm{~s}$. The test was also performed for the S235JR steel control material and was carried out under the same conditions as for the other samples. The abrasive used in the test was $\mathrm{Al}_{2} \mathrm{O}_{3}$ with 120 grains. The relative intensity of abrasive wear was determined as the ratio of the loss of mass of the test sample to the loss of mass of the control sample.

\section{TEST RESULTS AND DISCUSSION}

Photos of microstructures obtained from the optical microscope revealed numerous coating defects characteristic for thermal spraying processes. Fig. 1 shows the microstructure of the AMI 100 coating on which the coating lamellae and partially untreated particles are visible. Furthermore, oxides and pores occur in the microstructure. The pore size of the coatings has a bimodal distribution [8]. After the spraying process, the coating displayed characteristic large horizontal cracks, which were formed both at the substrate and at the top layer. Different orientation and size of cracks indicate that they may have formed as a result of metal solidification [9]. In the spraying process, the oxides were formed primarily during the interaction of liquid metal droplets with oxygen in the air stream, and also immediately after settling before the liquid particle cooled. Oxides often have a characteristic spherical shape due to their immiscibility with molten metal [10].

Due to the presence of micro-cracks, cracks and pores in the microstructure, porosity is an important parameter determining the mechanical properties of the coating [11]. There are not many works on the nature of the pore distribution in the coating's microstructure. Moreover, there are no exact measurements of porosity, which significantly limits the results of the analysed microstructures $[12,13]$. Fig. 2 shows how to quantify the pores in the coating's structure. In the analysed SEM image of 95 MXC material, only pores were marked (not oxides and impurities). The average open porosity of the $95 \mathrm{MXC}$ non-polished coating was $19.90 \%$ (Table 1). The structure of 95 MXC shows much higher porosity before erosion (Fig. 2) than after erosion (Fig. 5, tab.1). The average values of the open pores post erosion test results for the AMI 100 coating are similar to the results obtained from the closed pores by optical microscopy. The open porosity of the coatings measured after the erosion tests of the AMI 100 layer was similar. AMI 100 monolayer coatings show the dependency between the obtained results of abrasion tests and erosion studies and open porosity. The intensity of erosion reduces with decreasing porosity and the intensity of abrasive wear for the polished coating increases relatively to the non-polished coating. For a 95

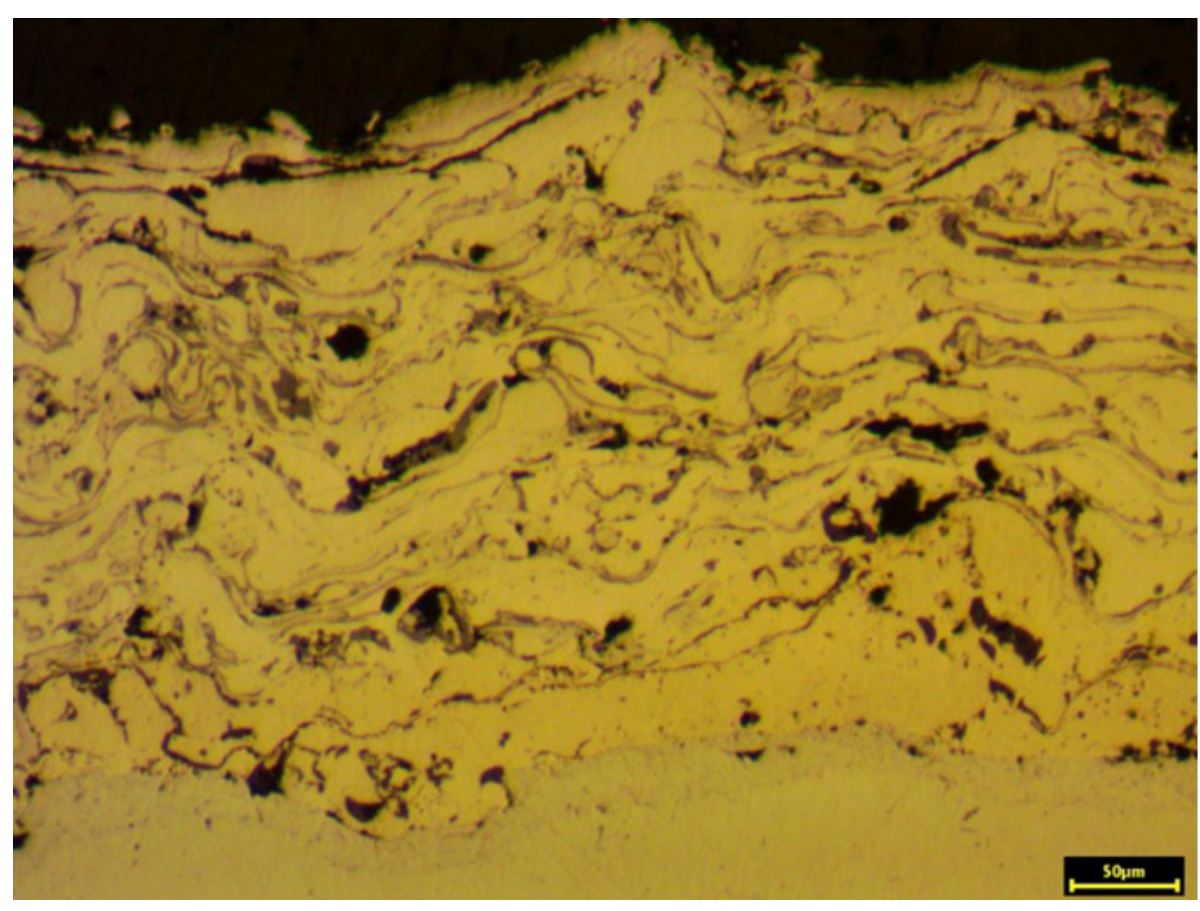

Fig. 1. Microstructure of AMI SPRAY ARC 100 powder coating with primer layer. 
Table 1. The average open porosity calculated based on SEM images

\begin{tabular}{|c|c|c|c|c|c|}
\hline AMI 100 & $\begin{array}{c}\text { AMl } 100 \text { eroded at } \\
\text { a } 30^{\circ} \text { angle }\end{array}$ & $\begin{array}{c}\text { AMl } 100 \text { eroded at } \\
\text { a } 90^{\circ} \text { angle }\end{array}$ & $95 \mathrm{MXC}$ & $\begin{array}{c}95 \mathrm{MXC} \text { eroded at } \\
\text { a } 30^{\circ} \text { angle }\end{array}$ & $\begin{array}{c}95 \mathrm{MXC} \text { eroded at } \\
\text { a } 90^{\circ} \text { angle }\end{array}$ \\
\hline $14.04 \%$ & $8.25 \%$ & $8.14 \%$ & $19.90 \%$ & $10.97 \%$ & $7.68 \%$ \\
\hline
\end{tabular}

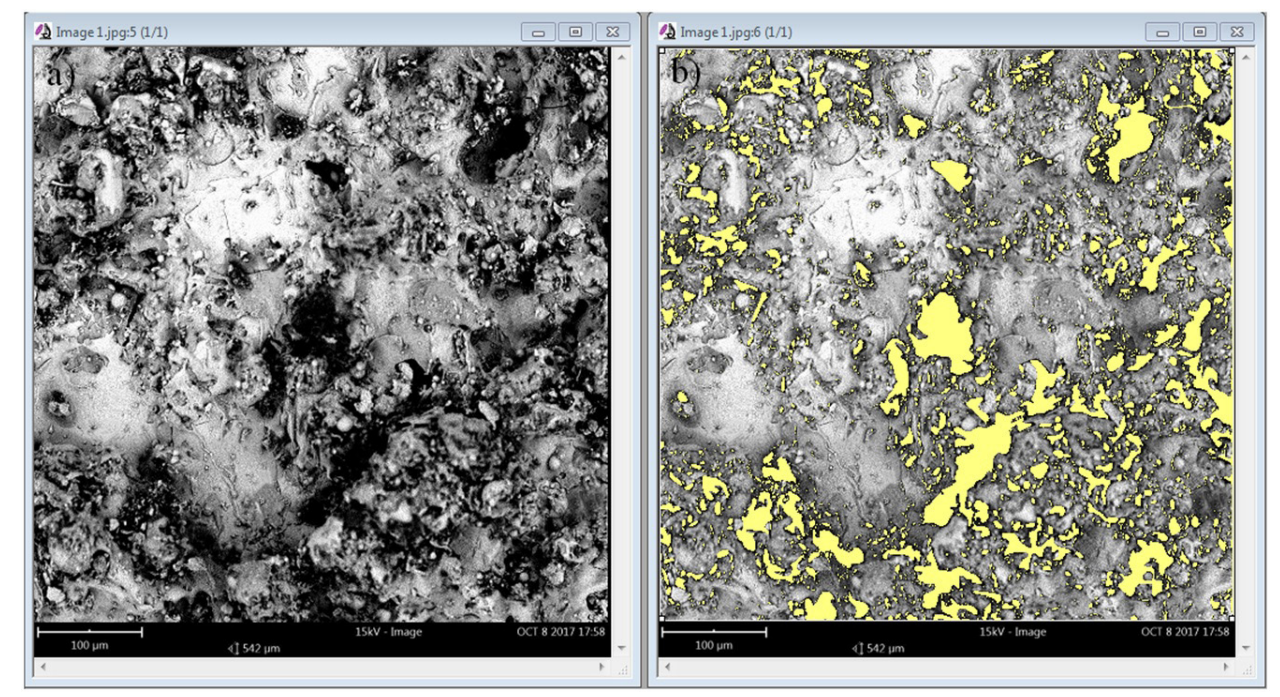

Fig. 2. SEM images: a) 95 MXC after spraying, b) analysis of open porosity in Image Pro Plus.

MXC non-polished coating, lower porosity was obtained after erosion with $90^{\circ}$ incidence angle than at a $30^{\circ}$ angle. Tables 1 and 3 prove that for the non-polished coating $95 \mathrm{MXC}$, with the decrease of open porosity, the relative intensity of erosive wear decreases.

The results for the closed porosity test based on SEM images are shown in Table 2, and the porosity results obtained from optical microscopy images are shown in Figure 3. During the analysis of the closed porosity based on SEM images and microstructures from optical microscopy, resulted in inconsistent data. The average porosity of $95 \mathrm{MXC}$ coatings (Fig. 3) was 5.49\%, and for AMI 100, 8.11\%. The porosity calculated on the basis of SEM images was about $2.4 \%$ for AMI 100 and about $1 \%$ for 95 MXC. Differences in results arose as a result of choosing the method

Table 2. Closed porosity calculated based on SEM images

\begin{tabular}{|c|c|c|}
\hline Coating & $\begin{array}{c}\text { The number of } \\
\text { images examined }\end{array}$ & $\begin{array}{c}\text { Average porosity } \\
(\%)\end{array}$ \\
\hline AMI 100 & 15 & 2.42 \\
\hline AMI $100+75 B$ & 15 & 2.45 \\
\hline 95 MXC & 15 & 1.09 \\
\hline 95 MXC $+75 B$ & 15 & 0.65 \\
\hline
\end{tabular}

of image analysis. In the microstructure studies with optical microscope, oxides are treated as porosity, as well as numerous propagation cracks in various directions. During porosity studies, the analysis of SEM images does not take into account larger cracks and large precipitations of oxides (oxides and inclusions are very well visible at high magnifications of SEM images, as shown in Fig. 2). Analysis of the closed porosity of SEM images revealed small pores at the grain boundaries caused by thermal contraction of the cooling metal particles.

The obtained results of microhardness measurements are characterised by quite large scattering of experimental data, which is typical for thermally sprayed coatings [14]. The results of microhardness measurements are shown in Fig. 4. The 95 MXC coatings with lower porosity than AMI 100 and Boron in chemical composition are characterised by much higher microhardness. Measured extreme values for the 95 MXC + primer layer are as high as $1800 \mathrm{HV}_{0.05}$, while the average values oscillate at the limit of 1150 $\mathrm{HV}_{0.05}$. For the examined coatings, the grouping of extreme results was observed, especially visible for $95 \mathrm{MXC}\left(1200 \div 1300 \mathrm{HV}_{0.05}\right)$. Coatings with the primer layer showed higher average microhardness values. The 75B/95 MXC coating, a significant increase in extreme values (above 


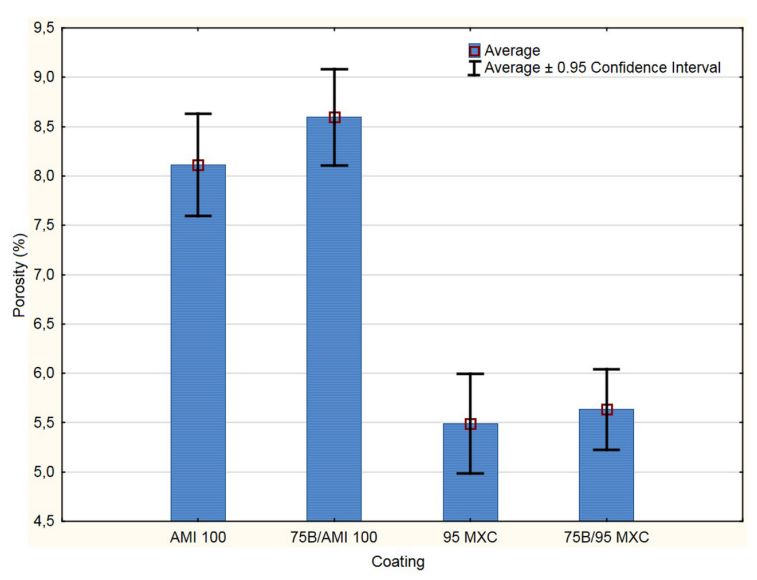

Fig. 3. Closed porosity calculations results for optical microscope images.

$\left.1500 \mathrm{HV}_{0.05}\right)$ was observed relative to the 95 MXC coating. The AMI 100 and 75B/AMI 100 coatings, the extreme lower values were similar, while the upper ones were higher for 75B/AMI 100. The average microhardness of the one and two-layered AMI 100 coatings was similar.

SEM images of the eroded coatings surface are shown in Fig. $5 \div 6$. During the coatings erosion, the surface layer of the material has been removed. Coatings eroded at an angle of $90^{\circ}$ are characterised by an even surface with numerous cracks and chippings of particles in the surface layer. The AMI 100 coating (Fig. 6-b) has a lower hardness than the 95 MXC coating (Fig. 5-b) and is characterised by a greater number of micro-

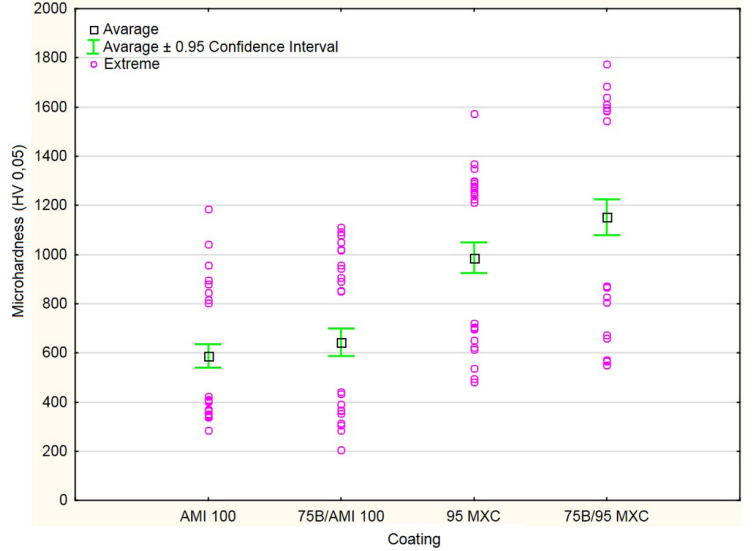

Fig. 4. Microhardness tests chart.

cracks and cavities similar to pores compared to the $95 \mathrm{MXC}$ coating. For coatings eroded at an angle of $30^{\circ}$ (Fig. 5-a, 6-a), defects in the coating due to chipping are less numerous than those eroded at an angle of $90^{\circ}$ (Fig. 5-b and 6-b). The main features of the eroded layers at an angle of $30^{\circ}$ (Figures 5-a and 6-a) are large pores, and visible micro-gaps in the structure (Fig. 5-a). The hard particles are removed when the matrix material around them has been eroded [1]. Additionally, the arrow in Fig. 6-a indicates the area with an increased carbon concentration (13\%). This may indicate the presence of carbide or carbide phase in this place. A large loss of the matrix is visible next to the marked area.
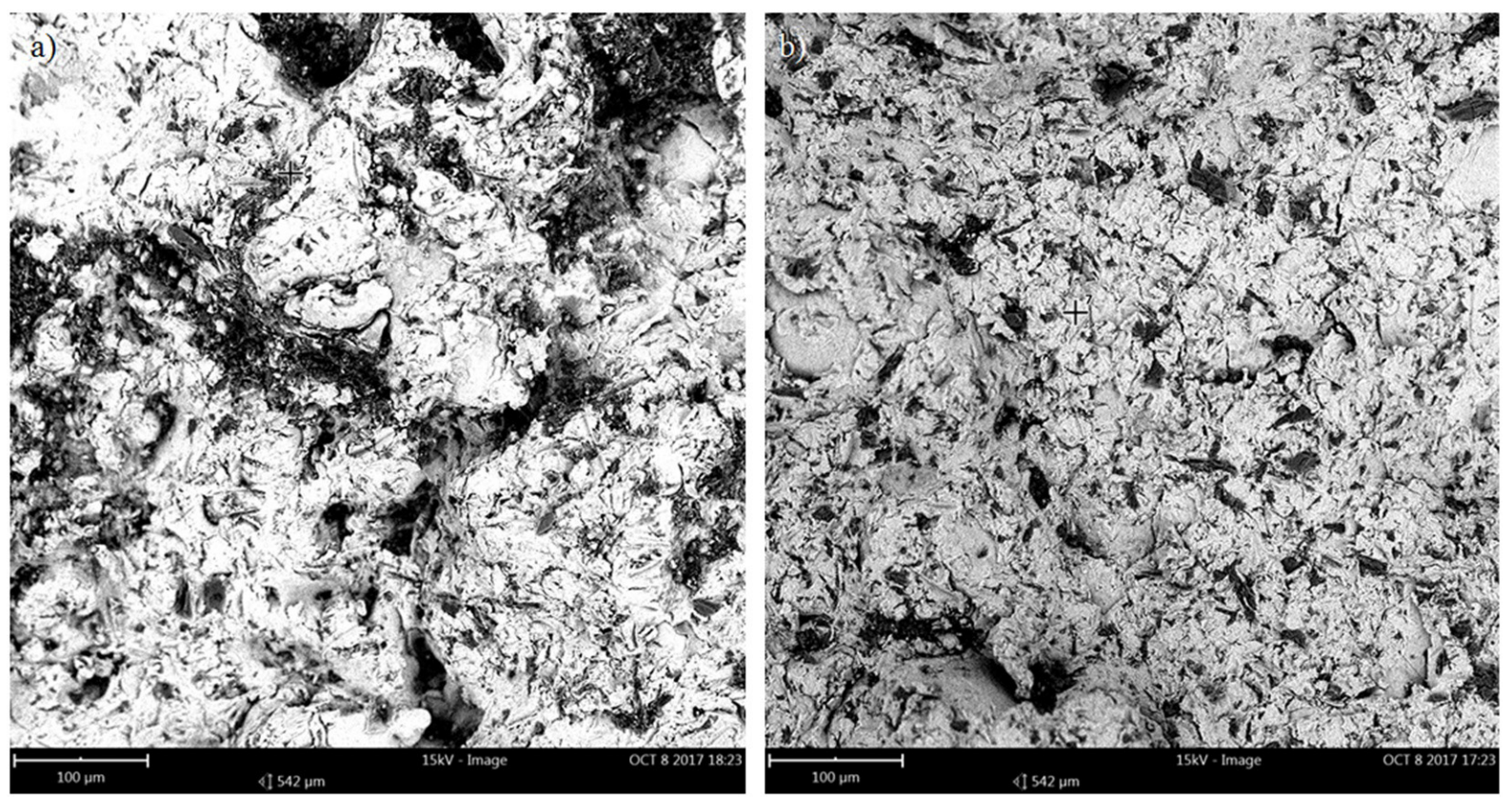

Fig. 5. SEM images: a) Surface of the $95 \mathrm{MXC}$ eroded at an angle of $30^{\circ}$, b) Surface of the $95 \mathrm{MXC}$ eroded at an angle of $90^{\circ}$. 

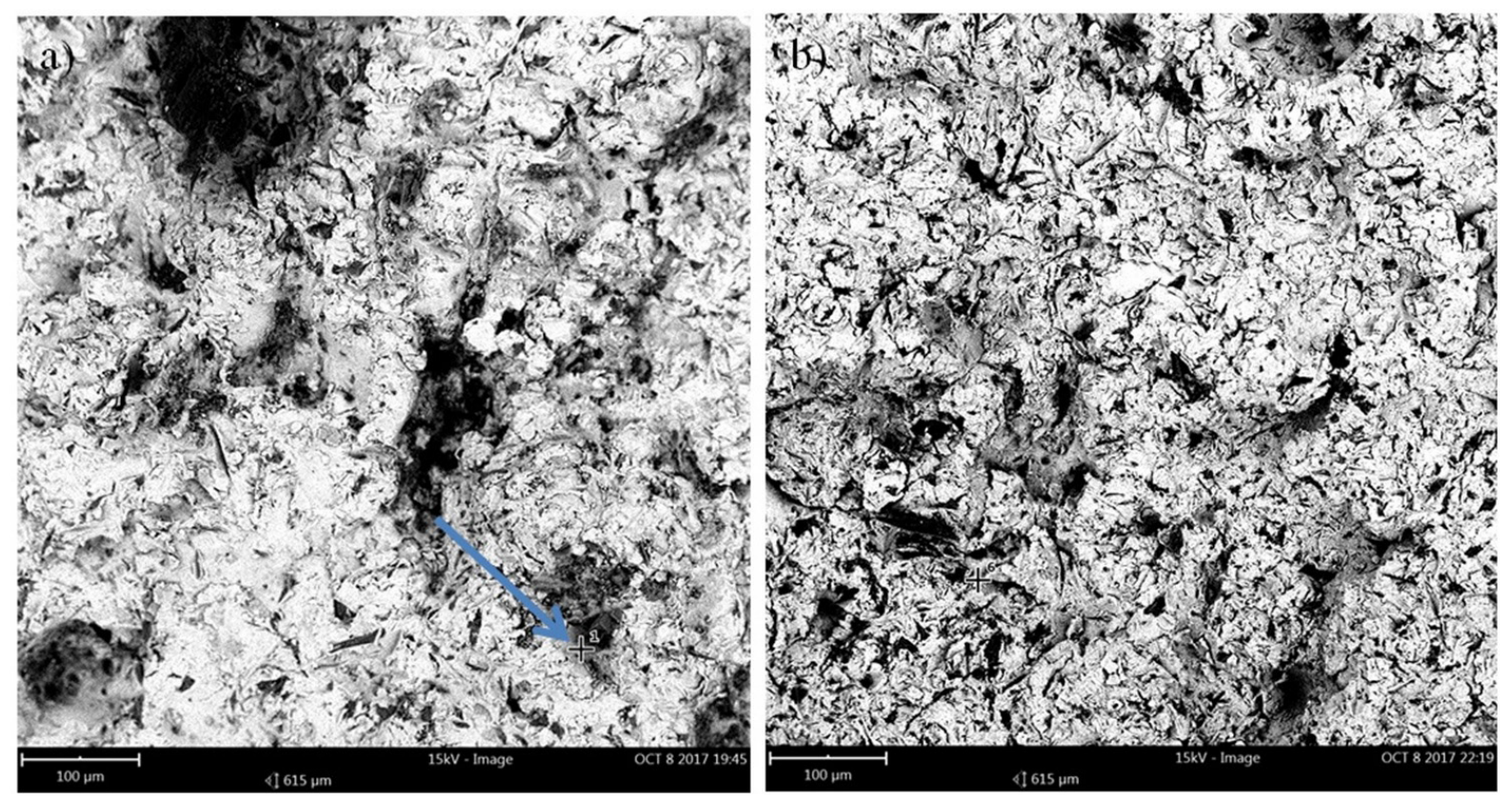

Fig. 6. SEM images: a) Surface of the AMI 100 eroded at an angle of $30^{\circ}$, b) Surface of the AMI 100 eroded at an angle of $90^{\circ}$.

The intensity of the tested erosion of the 95MXC monolayer coating and the two-layered $75 \mathrm{~B} / 95 \mathrm{MXC}$ coating is higher for an angle of incidence of $30^{\circ}$ than at the angle of $90^{\circ}$ (Table 3 ). The intensity of erosion of non-grounded coatings is about three times higher than the intensity of erosion of grounded coatings, which is associated with removing the unevenness of the coating during erosion. The $95 \mathrm{MXC}$ grounded and double-layered coating containing the $95 \mathrm{MXC}$ layer has a higher erosion intensity for a normal angle of incidence. The intensity of erosion of AMI 100 and double-layered 75B/AMI 100 coatings is higher at an angle of $30^{\circ}$. The difference in the intensity characteristics of the erosion of $95 \mathrm{MXC}$ and AMI 100 coatings is related to the hardness of the material [1]. For the AMI 100 coating, erosion tests at both $30^{\circ}$ and $90^{\circ}$ are varied. This is due to much lower hardness of the AMI 100 coating relative to the $95 \mathrm{MXC}$ coating. One and twolayer AMI 100 coatings show a lower intensity of erosive wear at a normal angle (Fig. 6-b). The AMI 100 coating was characterised by lower intensity of erosion wear for $95 \mathrm{MXC}$ non-ground coatings (especially at an angle of $30^{\circ}$ ). For AMI 100 and 75B/AMI 100 ground coatings, the erosive wear intensity was lower at an angle of $90^{\circ}$ with respect to $95 \mathrm{MXC}$ and 75B $95 \mathrm{MXC}$, and at an angle of $30^{\circ}$, these values were similar (except for the 95 MXC coating). The difference in the erosion resistance of one and two-layer coatings is related to different coating forming conditions and high internal stresses in the sprayed coatings. The porosity and hardness of the coating have a significant influence on erosion [15].

Wear-resistant coatings have been widely used, mostly for tribological applications for the protection of aluminium alloys [16]. The literature on the resistance of coatings to wear with different chemical compositions indicates that the nature of wear is closely related to the conditions of the test $[17,18]$. The intensity and nature of abrasive wear is influenced by many factors such as: porosity, chemical composition of the coating, number of inclusions, cracks or parameters of the spraying process. Table 4 shows the results of abrasive wear tests. Coatings with primer layers showed higher average abrasion intensity than coatings without a primer. The $95 \mathrm{MXC}$ coatings without a primer layer with boron in their chemical composition are characterised by a lower relative intensity of abrasive wear in relation to AMI 100 coatings. An important aspect is the results obtained for 95 MXC and AMI 100 ground coatings where the relative intensity of abrasive wear is significantly higher than that of non-ground coatings. The results for the AMI 100 and 95 MXC monolayer coatings are related to the fact that when trying to abrade the rough coating, the abrasive grains occupy space in the unevenness of the coating. They provide support for countersample, which has reduced abrasive wear. For 
Table 3. Results from erosive wear tests.

\begin{tabular}{|c|c|c|c|c|}
\hline Material & $\begin{array}{c}\text { Average erosion } \\
\text { intensity [mg/g] (for } \\
90^{\circ} \text { angle) }\end{array}$ & $\begin{array}{c}\text { Average erosion } \\
\text { intensity [mg/g] (for } 30^{\circ} \\
\text { angle) }\end{array}$ & $\begin{array}{c}\text { Average erosion intensity } \\
{[\mathrm{mg} / \mathrm{g}] \text { (for } 90^{\circ} \text { angle), }} \\
\text { ground surface }\end{array}$ & $\begin{array}{c}\text { Average erosion intensity } \\
{[\mathrm{mg} / \mathrm{g}] \text { (for } 30^{\circ} \text { angle), }} \\
\text { ground surface }\end{array}$ \\
\hline $95 \mathrm{MXC}$ & 2.18 & 2.37 & 0.79 & 0.57 \\
\hline $95 \mathrm{MXC}+75 \mathrm{~B}$ & 2.13 & 2.35 & 1.2 & 0.78 \\
\hline AMI 100 & 1.75 & 1.77 & 0.62 & 0.74 \\
\hline AMI 100 + 75B & 1.45 & 1.62 & 0.72 & 0.82 \\
\hline
\end{tabular}

75B/95MXC and 75B/ AMI 100 coatings, the relative intensity of abrasive wear is higher for non-ground coatings. No influence of porosity on abrasive wear intensity tests was observed.

To determine the strength of the bond between the coating and the base, adhesion tests were carried out in accordance with DIN EN 582. The results are presented in Table $5 \div 6$. Adhesion of the coating is one of the decisive factors determining its applicability. Factors such as chemical properties of the material, base roughness, coefficients of thermal expansion of the base, coatings, as well as factors related to the deposition process (such as microstructure, internal stresses, thickness and presence of impurities, and structural defects in the coating) affect the adhesion of the coating to the base $[19,20]$. The highest adhesion was noted for materials sprayed on 10CrMo9-10 steel. The highest adhesion tested was noted for the $95 \mathrm{MXC}$ sample and it was $35.67 \mathrm{MPa}$. Higher adhesion was obtained by coatings characterised by high elongation of the tested sample. The minimum adhesion of the AMI 100 coating sprayed on 13CrMo4-5 and 10CrMo9-10 steels is similar, but the average maximum values are much higher. In the adhesion tests of the 95MXC coating, a similar dependence is observed. The fractures were mixed (cohesive-adhesive). Differences in elongation are associated with different cohesion and adhesion rates.

\section{CONCLUSIONS}

Microstructure investigations revealed numerous cracks between the coating and the base material, as well as in the top layer of the coating. The pores observed between the coating and the substrate could have a significant effect on the adhesion parameter. The intensity of erosion wear at an angle of $30^{\circ}$ to the angle of $90^{\circ}$ is higher in non-ground coatings. Open porosity is dependent to the angle of erosion. For AMI 100 coatings, eroded with incidence angle $30^{\circ}$ and $90^{\circ}$, the open porosity is similar to the results of closed porosity calculated on the basis of optical microscope images. Closed porosity measured from SEM images is several times lower than average porosity results from light microscopy images. The relative intensities of abrasive wear of ground and non-ground coatings are similar to each other. The coatings sprayed on 10CrMo9-10 steel show higher adhesion in tensile tests. The coatings sprayed onto the primer layer 75B show higher microhardness. The AMI 100 coatings show the presence of the carbide phases. The $95 \mathrm{MXC}$ coatings containing $3.3-4 \%$ boron, allowed for forming of carbide and boride phases, with a hardness of $1200 \div 1300 \mathrm{HV}_{0.05}$ (for $95 \mathrm{MXC}$ ) and $1500 \div 1700 \mathrm{HV}_{0.05}$ (for 75B/95 MXC coating). The described coatings are suitable for use in heat exchangers such as the $\mathrm{OP}-215$ energy boiler.

Table 4. Results from abrasive wear tests.

\begin{tabular}{|c|c|c|c|c|}
\hline & $95 \mathrm{MXC}$ & $75 \mathrm{~B} / 95 \mathrm{MXC}$ & AMI 100 & $75 \mathrm{~B} / \mathrm{AMI} 100$ \\
\hline $\begin{array}{c}\text { Relative average intensity of } \\
\text { abrasive wear of non-ground } \\
\text { coatings }\end{array}$ & 0.96 & 1.31 & 1.11 & 1.42 \\
\hline $\begin{array}{c}\text { Relative average intensity } \\
\text { of abrasive wear (for ground } \\
\text { coating) }\end{array}$ & 1.13 & 1.27 & 1.55 & 1.35 \\
\hline
\end{tabular}

Table 5. Test results from the AMI SD 6.5 + 95 MXC tensile test.

\begin{tabular}{|c|c|c|c|c|}
\hline Base material & Average elongation (\%) & Elongation - range (\%) & Average adhesion (MPa) & Adhesion range (MPa) \\
\hline 13CrMo4-5 & 4.11 & $2.81-5.43$ & 16.31 & $12.43-22.01$ \\
\hline 10CrMo9-10 & 5.69 & $3.42-8.83$ & 22.45 & $11.5-35.67$ \\
\hline
\end{tabular}


Table 6. Test results from the AMI SD 6.5 + AMI SPRAY ARC 100 tensile test.

\begin{tabular}{|c|c|c|c|c|}
\hline Base material & Average elongation (\%) & Elongation - range (\%) & $\begin{array}{c}\text { Average adhesion } \\
(\mathrm{MPa})\end{array}$ & Adhesion range (MPa) \\
\hline 13 CrMo4-5 & 3.33 & $1.93-6.45$ & 14.39 & $8.38-28.7$ \\
\hline 10 CrMo9-10 & 4.97 & $1.93-6.52$ & 24.72 & $9.01-34.3$ \\
\hline
\end{tabular}

\section{REFERENCES}

1. Hejwowski T.: Nowoczesne powłoki nakładane cieplnie odporne na zużycie ścierne i erozyjne. Politechnika Lubelska, Lublin 2013

2. Solski P.: Zużycie cierne metali, WNT Warszawa 1968.

3. Winter, R.E., Hutchings, I.M.: Solid particle erosion studies using single angular particles. Wear 1974, vol. 29, str. 181 - 194.

4. Parslow G.I., Stephenson D.J., Strutt J.E., Tetlow S.: Investigation of solid particle erosion in components of complex geometry. Wear 1999, vol. 233-235, str. 737-745.

5. Bergmann C.P., Vincenzi J.: Protection against erosive wear using thermal sprayed cermet. A review. Springer-Verlag, Berlin, 2011.

6. Hejwowski T.: Studium procesów zużywania erozyjnego, ściernego i zmęczenia cieplnego elementów maszyn oraz kształtowanie struktur o korzystnych właściwościach eksploatacyjnych. Wydawnictwo Uczelniane Politechniki Lubelskiej 2003.

7. Venugopal K., Agrawal M.: Evaluation of arc sprayed coatings for erosion protection of tubes in atmospheric fluidized bed combustion (AFBC) boilers. Wear 2008, vol. 264, str. 139-145.

8. Lima R.S., Marple B.R.: Thermal spray coatings engineered from nanostructured ceramic agglomerated powders for structural, thermal barrier and biomedical applications: a review. Journal of Thermal Spray Technology 2007, vol. 16, nr 1, str. 40-63.

9. Xuemei S., Fangli M.,Mingguang K.,Ziwei L.,Liping H.,Xuebin Z., Yi Z.: Relationship between cracks and microstructures in APS YSZ coatings at elevated temperatures. Materials Characterization, Volume 131, September 2017, Pages 277-284.

10. Deshpande S., Sampath S., Zhang H.: Mechanisms of oxidation and its role in microstructural evolution of metallic thermal spray coatings - case study for Ni-Al. Surf. Coat. Technol., 200 (2006), pp. 5395-5406

11. Chao Z.,Wei T. i inni: Microstructure and porosity evaluation in laser-cladding deposited Ni- based coatings. Surface and Coatings Technology. Volume 294, 25 May 2016, Pages 122-130

12. F. Cernuschi, I.O. Golosnoy, P. Bison, A. Moscatel- li, R. Vassen, H.P. Bossmann, S. Capelli: Microstructural characterization of porous thermal barrier coatings by IR gas porosimetry and sintering forecasts. Acta Mater., 61 (1) (2013), pp. 248-262

13. Wang Y., Gauvin R. i inni: Panoramic statistics on porosity and microstructural features of plasma sprayed $\mathrm{Y} 2 \mathrm{O} 3-\mathrm{ZrO} 2$ thermal barrier coatings. Surface and Coatings Technology. Volume 316, 25 April 2017, Pages 239-245

14. Giovanni B., Marcello B., Luca L., Tiziano M., Ville M., Rinaldo R., Paolo S., Petri V.: Tribology of FeVCrC coatings deposited by HVOF and HVAF thermal spray processes. WearVolumes 394-395, 15 January 2018, Pages 113-133.

15. Lei Q., Yuping W.,Sheng H.,Jianfeng Z., Wei S., Yugui Z.: Relationships between spray parameters, microstructures and ultrasonic cavitation erosion behavior of HVOF sprayed Fe- based amorphous/nanocrystalline coatings. Ultrasonics Sonochemistry. Volume 39, November 2017, Pages 39-46

16. G. Bolelli, B. Bonferroni, G. Coletta, L. Lusvarghi, F. PitaccoWear and corrosion behaviour of $\mathrm{HVOF}$ WC-CoCr/CVD DLC hybrid coating systems deposited onto aluminium substrate. Surf. Coat. Technol., 205 (2011), pp. 4211-4220

17. F. Madah, C. Dehghanian, A.A. Amadeh: Investigations on the wear mechanisms of electroless Ni-B coating during dry sliding and endurance life of the worn surfaces. Surf. Coat. Technol., 282 (2015), pp. 6-15

18. M. Magnani, P.H. Suegama, N. Espallargas, S. Dosta, C.S. Fugivara, J.M. Guilemany, A.V. B enedetti: Influence of HVOF parameters on the corrosion and wear resistance of WC-Co coatings sprayed on AA7050 T7.Surf. Coat. Technol., 202 (2008), pp. 4746-4757

19. Shigeyasu A.,Tohru H.: Planar fractal characteristics of blasted surfaces and its relation with adhesion strength of coatings. Surface and Coatings Technology. Volume 130, Issues 2-3, 21 August 2000, Pages 158-163

20. Drábik M.,Truchlý M.,Ballo V.,Roch T., Kvetková L.,Kúš P.: Influence of substrate material and its plasma pretreatment on adhesion and properties of WC/a-C:H nanocomposite coatings deposited at low temperature. Surface and Coatings Technology. Volume 333, 15 January 2018, Pages 138-147 